\title{
Factors associated with improvement in sagittal spinal alignment after microendoscopic laminotomy in patients with lumbar spinal canal stenosis
}

\author{
Sho Dohzono, MD, PhD, ${ }^{1}$ Hiromitsu Toyoda, MD, PhD, ${ }^{1}$ Shinji Takahashi, MD, PhD, ${ }^{1}$ \\ Tomiya Matsumoto, MD, PhD, ${ }^{2}$ Akinobu Suzuki, MD, PhD, ${ }^{1}$ Hidetomi Terai, MD, PhD, ${ }^{1}$ and \\ Hiroaki Nakamura, MD, PhD'

\begin{abstract}
'Department of Orthopaedic Surgery, Osaka City University Graduate School of Medicine, Osaka; and 'Department of Orthopaedic Surgery, Osaka Rosai Hospital, Osaka, Japan
\end{abstract}

\begin{abstract}
OBJECTIVE Little is known about the relationship between sagittal spinal alignment in patients with lumbar spinal canal stenosis (LSS) and objective findings such as spinopelvic parameters, lumbar back muscle degeneration, and clinical data. The purpose of this study was to identify the preoperative clinical and radiological factors that predict improvement in sagittal spinal alignment after decompressive surgery in patients with LSS.

METHODS The records of 61 patients with LSS who underwent microendoscopic laminotomy and had pre- and postoperative clinical data collected were retrospectively reviewed. Spinopelvic parameters, including sagittal vertical axis (SVA), lumbar lordosis (LL), sacral slope, pelvic tilt, and pelvic incidence (PI), were evaluated. On T2-weighted MRI, the cross-sectional area and the percentage of fat infiltration of the paravertebral muscles (PVMs) before surgery were calculated. For patients with preoperative SVA $>40 \mathrm{~mm}(n=30)$, the correlation between SVA improvement and preoperative clinical and radiographic parameters was calculated.
\end{abstract}

RESULTS SVA improvement correlated with preoperative LL $(r=-0.39)$ and $\mathrm{PI}-\mathrm{LL}(r=0.54)$. Multiple regression analysis showed that preoperative $\mathrm{PI}-\mathrm{LL}$ (beta $=0.62 ; p<0.01$ ) and symptom duration (beta $=-0.40 ; p<0.05$ ) were independently associated with SVA improvement. The percentage of fat infiltration of the PVM at L4-5 was significantly greater in patients with preoperative SVA $\geq 40 \mathrm{~mm}$ than in those patients with $S V A<40 \mathrm{~mm}$.

CONCLUSIONS Preoperative PI - LL and symptom duration were independently associated with SVA improvement in LSS patients with forward-bending posture. PVM degeneration at the lower lumbar level was significantly greater among patients with preoperative $S V A \geq 40 \mathrm{~mm}$ than in patients with $S V A<40 \mathrm{~mm}$.

http://thejns.org/doi/abs/10.3171/2015.12.SPINE15805

KEY WORDS microendoscopic lumbar decompression; sagittal vertical axis; C-7 plumb line; spinopelvic parameter; paravertebral muscle degeneration; fat infiltration

S AGITTAL balance of the spine is important in the management of lumbar diseases and low-back pain (LBP). ${ }^{1,9,10}$ The sagittal vertical axis (SVA) (Fig. 1) - defined as the deviation of the C-7 plumb line from the posterior corner of the sacrum-has been associated with health-related quality of life (QOL).,16 In patients with lumbar spinal canal stenosis (LSS), symptomatic relief is obtained by standing or walking with lumbar flexion. ${ }^{20} \mathrm{~A}$ correlation has been reported between sagittal spinal alignment and clinical outcome in patients with lumbar disease. ${ }^{5,19}$ We previously reported that a preop- erative forward-bending posture was associated with LBP before and after microendoscopic laminectomy (MEL) in patients with LSS. ${ }^{4}$

Evaluation of the lumbar back muscles is also important when treating lumbar diseases because LBP and spinopelvic imbalance are associated with back muscle degeneration. ${ }^{3,12,14}$ Moreover, QOL is related to back muscle strength, and poor functional performance in patients with LSS is related to fatty degeneration of the paravertebral muscles (PVMs). ${ }^{2}$

Spinopelvic parameters, including SVA, lumbar lordo-

ABBREVIATIONS CSA = cross-sectional area; JOA = Japanese Orthopaedic Association; LBP = low-back pain; LL = lumbar lordosis; LSS = lumbar spinal canal stenosis; $\mathrm{MEL}=$ microendoscopic laminectomy; $\mathrm{PI}=$ pelvic incidence; $\mathrm{PT}=$ pelvic tilt; $\mathrm{PVM}=$ paravertebral muscle; $\mathrm{QOL}=$ quality of life; $\mathrm{SS}=$ sacral slope; $\mathrm{SVA}=$ sagittal vertical axis; VAS = visual analog scale; $\% \mathrm{FI}=$ percentage of fat infiltration.

SUBMITTED July 9, 2015. ACCEPTED December 9, 2015.

INCLUDE WHEN CITING Published online March 11, 2016; DOI: 10.3171/2015.12.SPINE15805. 


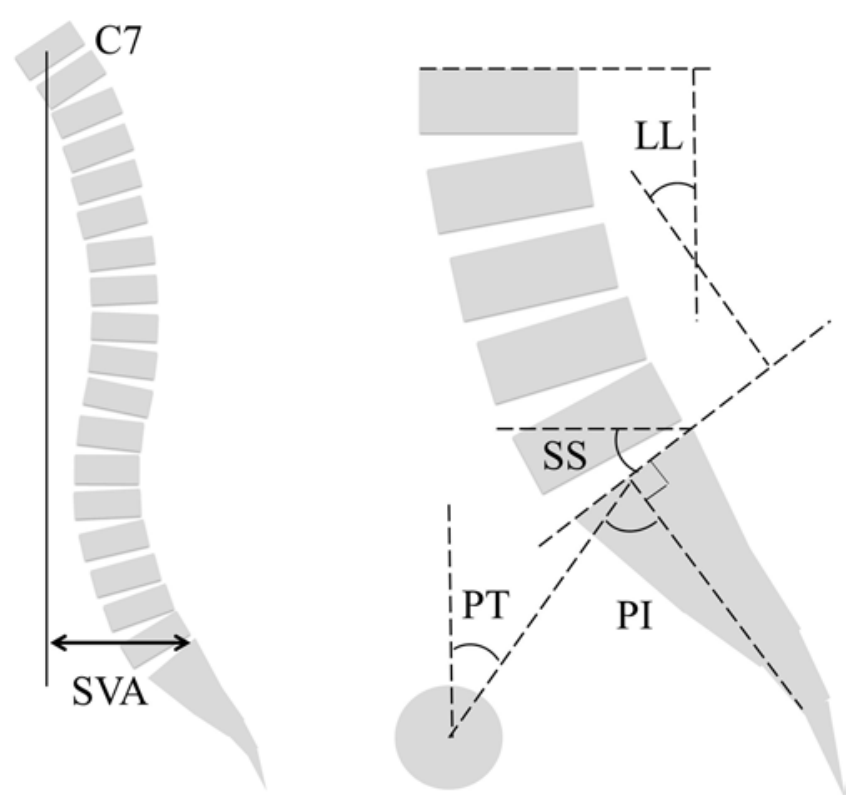

FIG. 1. Illustration showing the sagittal spinopelvic parameters, including SVA, LL, SS, PT, and PI.

sis (LL), sacral slope (SS), pelvic tilt (PT), and pelvic incidence (PI) (Fig. 1), have been used in the management of adult spinal deformity. However, in patients with LSS, little is known about the relationship between sagittal spinal alignment and objective findings, such as spinopelvic parameters, degeneration of the lumbar back muscles, and clinical data. The present study aimed to determine whether any preoperative clinical and radiological factors predict improvement in sagittal spinal alignment after decompressive surgery in patients with LSS. We also evaluated differences in PVM degeneration according to preoperative SVA.

\section{Methods}

This study was approved by the Institutional Review Board of Osaka City University Graduate School of Medicine.

The records of 73 patients who underwent MEL for LSS at our institution between August 2008 and October 2012 were retrospectively reviewed. All patients had experienced lower-extremity pain and/or numbness. The minimum duration of clinical and radiological follow-up was 1 year. Of the 73 patients considered for inclusion in the analysis, 12 were excluded: 7 were lost to follow-up, 4 had a history of previous spinal surgery, and 1 had a vertebral fracture. The remaining 61 patients (30 men and 31 women), with a mean age of 69.4 years (range 47-86 years), were included in this study. The mean duration of symptoms before surgery was 3.8 years (range 4 months to 20 years), and patients were observed for a mean duration of 19.1 months after surgery (range 12-48 months).

Twenty-three patients had degenerative spondylolisthesis $(>3 \mathrm{~mm})$, and 12 had scoliotic disc wedging $\left(>3^{\circ}\right)$ at the affected level. The exclusion criteria for the use of this surgical procedure in patients with degenerative spon- dylolisthesis were percent slip $>25 \%$ and segmental kyphosis in flexion $>5^{\circ}$. Exclusion criteria in patients with degenerative lumbar scoliosis were a Cobb angle $>25^{\circ}$, severe LBP, changes in segmental disc wedging between standing and prone position $>5^{\circ}$, and lateral disc slippage $>3 \mathrm{~mm}^{4}{ }^{4}$

Fifty-seven patients underwent decompression at a single level (49 patients at L4-5, 7 patients at L3-4, and 1 patient at L5-6), and 4 patients underwent decompression at 2 levels (3 patients at L3-5 and 1 patient at L2-4).

\section{Clinical Evaluation}

Surgical outcomes were evaluated using the Japanese Orthopaedic Association (JOA) score for LBP. The JOA score and visual analog scale (VAS) ratings for LBP, leg pain, and leg numbness were collected before surgery and at the final follow-up. The VAS rating for pain or numbness intensity ranged from 0 to 100 and was anchored by "no pain or numbness" (score 0) and "worst imaginable pain or numbness" (score 100). These data were collected at standardized times: before surgery and at 6 months, 1 year, and 2 years after surgery. The JOA score improvement ratio was calculated as (postoperative JOA score preoperative JOA score) / (29 - preoperative JOA score) $\times 100(\%)$. The VAS score improvement $(\mathrm{mm})$ was calculated as (preoperative VAS score) - (postoperative VAS score).

\section{Radiological Evaluation}

Three authors (S.D., H. Toyoda., and T.M.) measured the images and were blinded to outcomes. SVA, LL, SS, PT, and PI were measured on lateral standing radiographs of the entire spine that were obtained before surgery and at the final follow-up, as described by Jackson and McManus. ${ }^{9}$ The mean time to obtaining the lateral standing radiographs at the final follow-up was $29.9 \pm 14.8$ months. Improvement in SVA and PT were calculated as (value before surgery) - (value at final follow-up), and LL improvement was calculated as (value at final follow-up) - (value before surgery).

\section{Evaluation of PVM on MR Images}

Axial T2-weighted MR images were chosen for PVM evaluation. The bilateral PVM volume was calculated by aggregating the cross-sectional area (CSA) of the multifidus and erector muscles before surgery at L2-3, L3-4, and L4-5 using ImageJ 1.48 (released by the National Institutes of Health) (Fig. 2). The percentage of fat infiltration $(\% \mathrm{FI})$ was assessed using a previously reported threshold technique. ${ }^{12,18}$ CSA and \%FI of the PVM were statistically compared between patients with SVA $\geq 40 \mathrm{~mm}$ and those with SVA $<40 \mathrm{~mm}$.

\section{Factors Associated With Improvement in Sagittal Spinal Alignment}

Improvement in SVA was defined as the difference between SVA before surgery and the final follow-up: (SVA before surgery) - (SVA at the latest follow-up). For patients with a preoperative SVA $\geq 40 \mathrm{~mm}(\mathrm{n}=30)$, the relationship between SVA improvement and preoperative 


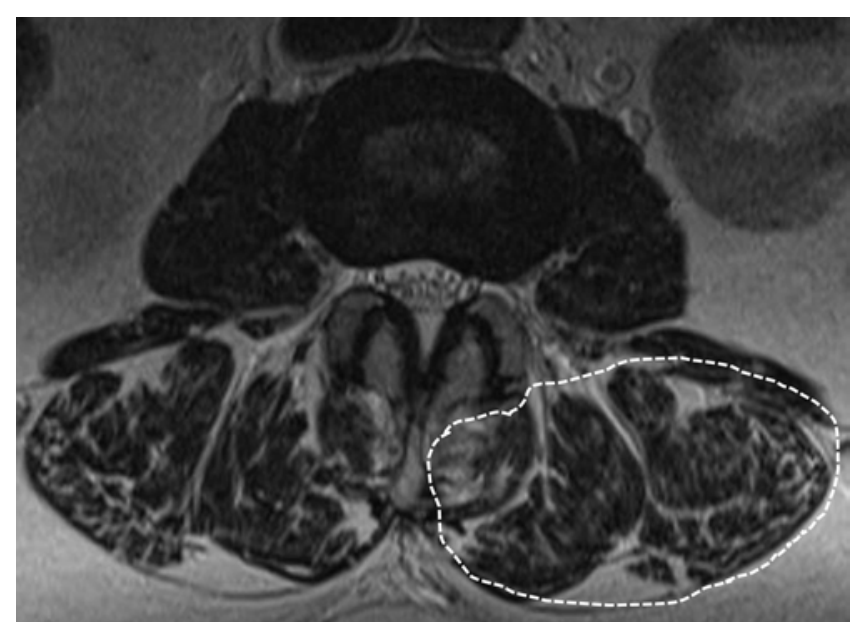

FIG. 2. Magnetic resonance image showing the measurement of the CSA of the PVM (dotted circle).

clinical data and radiographic parameters was analyzed using multiple regression analysis.

\section{Deformity Subgroup Analyses}

Patients with a preoperative SVA $\geq 40 \mathrm{~mm}$ were divided into 2 groups: the deformity group (Group D: degenerative spondylolisthesis [ $>3 \mathrm{~mm}$ ] or scoliotic disc wedging $\left[>3^{\circ}\right]$ at the affected level) and the no deformity group (Group N). Sixteen patients were allocated to Group D (6 male and 10 female patients) and 14 patients to Group $\mathrm{N}$ (7 male and 7 female patients). Clinical outcomes were statistically compared between the 2 groups.

\section{Clinical Outcomes According to the Change in SVA}

We grouped patients according to the change in the SVA after MEL: the SVA-improved group (postoperative - preoperative value $<0$ ) and the SVA-increased group (postoperative - preoperative value $\geq 0$ ). The JOA score improvement ratio and VAS improvements in LBP, leg pain, and leg numbness were statistically compared between the 2 groups.

\section{Statistical Analysis}

Statistical analyses were performed using IBM SPSS Statistics (version 19, IBM SPSS Inc.), and $p$ values $<0.05$ were considered statistically significant. To evaluate the reliability of the CSA and \%FI measurements of the PVM, intra- and interobserver variabilities were evaluated. Two spine surgeons (S.D. and S.T.), who were blind to the patients' clinical data, independently measured the parameters. After each surgeon had measured a parameter twice, the intra- and interobserver variabilities were evaluated as the intraclass coefficient of correlation. Parametric analyses were performed with the Student t-test or paired t-test. Nonparametric analyses were performed using the MannWhitney U-test. Categorical variables were analyzed using the chi-square test.

For patients whose preoperative SVA values were > $40 \mathrm{~mm}$, the Pearson product moment correlation coeffi-
TABLE 1. Radiographic and clinical data

\begin{tabular}{|c|c|c|c|}
\hline Variable & Preop* & At Latest Follow-Up* & $\mathrm{p}$ Value \\
\hline SVA $(\mathrm{mm})$ & $45.5 \pm 37.4$ & $36.7 \pm 36.9$ & 0.082 \\
\hline $\operatorname{LL}\left({ }^{\circ}\right)$ & $25.6 \pm 16.0$ & $28.0 \pm 16.4$ & 0.038 \\
\hline $\operatorname{SS}\left({ }^{\circ}\right)$ & $29.7 \pm 7.9$ & $30.1 \pm 10.2$ & 0.607 \\
\hline $\mathrm{PT}\left({ }^{\circ}\right)$ & $19.4 \pm 8.1$ & $19.4 \pm 9.9$ & 0.957 \\
\hline $\mathrm{PI}\left({ }^{\circ}\right)$ & $48.9 \pm 9.5$ & $49.3 \pm 10.1$ & 0.251 \\
\hline $\mathrm{PI}-\mathrm{LL}\left({ }^{\circ}\right)$ & $23.2 \pm 15.0$ & $21.3 \pm 15.3$ & 0.100 \\
\hline JOA score (points) & $14.0 \pm 4.4$ & $25.1 \pm 3.6$ & $<0.01$ \\
\hline \multicolumn{4}{|l|}{ VAS score } \\
\hline LBP & $45.7 \pm 30.4$ & $15.7 \pm 22.5$ & $<0.01$ \\
\hline Leg pain & $61.6 \pm 28.0$ & $17.3 \pm 27.8$ & $<0.01$ \\
\hline Leg numbness & $48.8 \pm 29.2$ & $24.3 \pm 28.2$ & $<0.01$ \\
\hline
\end{tabular}

cient was calculated between SVA improvement and the following variables obtained before surgery: age, symptom duration, JOA score, VAS score (LBP, leg pain, and numbness), LL, SS, PT, PI, PI - LL, CSA of PVM, and $\% \mathrm{FI}$ of PVM. Multiple regression analysis was used to evaluate the factors independently associated with SVA improvement. Variables included in the multivariate model were those with a $\mathrm{p}$ value $<0.2$ in the univariate analysis.

\section{Results}

The SVA decreased in 39 of 61 patients (69.3\%) who underwent MEL. Twenty-two patients (36.1\%) had an increase in SVA. The mean SVA value decreased from 45.5 $\mathrm{mm}$ (range -36 to $162 \mathrm{~mm}$ ) before surgery to $36.7 \mathrm{~mm}$ (range -43 to $49 \mathrm{~mm}$ ) at the latest follow-up; however, the difference was not significant $(\mathrm{p}=0.082)$. LL increased in 33 of 61 patients (54.1\%) who underwent MEL. LL significantly increased from $25.6^{\circ}$ (range $-45^{\circ}$ to $50^{\circ}$ ) to $28.0^{\circ}$ at the latest follow-up (range $-31^{\circ}$ to $49^{\circ} ; \mathrm{p}=0.038$ ). There were no significant differences between pre- and postsurgical values for SS, PT, PI, or PI - LL. The JOA and VAS scores for LBP, leg pain, and numbness significantly improved after MEL (Table 1).

Among patients with a preoperative $\mathrm{SVA} \geq 40 \mathrm{~mm}$ ( $\mathrm{n}=$ 30), 2 of 7 patients with a preoperative SVA $\geq 95 \mathrm{~mm}$ and 8 of 23 patients with a preoperative SVA between 40 and $95 \mathrm{~mm}$ had improvement in SVA to $<40 \mathrm{~mm}$ (Table 2).

SVA improvement in the patients with preoperative $\mathrm{SVA} \geq 40 \mathrm{~mm}(20.4 \pm 44.7)$ was significantly higher than those of the patients with preoperative SVA $<40 \mathrm{~mm}$ $(-2.4 \pm 28.9 ; \mathrm{p}=0.02)$. LL improvement in the patients with preoperative SVA $\geq 40 \mathrm{~mm}(4.6 \pm 7.8)$ tended to be higher than those of the patients with preoperative SVA < $40 \mathrm{~mm}(0.3 \pm 9.6 ; \mathrm{p}=0.06)$ (Table 3$)$.

\section{CSA and \%FI of the PVM}

The intraobserver intraclass coefficient of the correlation values for the CSA and \%FI of PVM were 0.94 and 0.88 , respectively; the interobserver values were 0.94 and 0.83 , respectively, indicating that the measurements were 
TABLE 2. Number of patients according to SVA before surgery and at the latest follow-up

\begin{tabular}{crcc}
\hline & \multicolumn{3}{c}{ Preop SVA (mm) } \\
\cline { 2 - 4 } SVA at Latest Follow-Up $(\mathrm{mm})$ & $<40$ & $40-95$ & $>95$ \\
\hline$<40$ & 27 & 8 & 2 \\
\hline $40-95$ & 3 & 13 & 3 \\
\hline$>95$ & 1 & 2 & 2 \\
\hline
\end{tabular}

reliable. ${ }^{11}$ The CSA of the PVM at L4-5 tended to be low in patients with preoperative SVA $\geq 40 \mathrm{~mm}(40.7 \pm 9.8$ $\left.\mathrm{cm}^{2}\right)$ compared with those with SVA $<40 \mathrm{~mm}(45.3 \pm$ $10.4 \mathrm{~cm}^{2}$ ). The $\%$ FI of the PVM at L4-5 was significantly higher in patients with a preoperative SVA $\geq 40 \mathrm{~mm}(33.0$ $\pm 11.1 \%)$ than in those with SVA $<40 \mathrm{~mm}(26.0 \pm 12.3 \%)$. The CSA and \%FI of the PVM at L2-3 and L3-4 were not significantly different between the groups that were divided according to preoperative SVA (Table 3).

\section{Factors Associated With Improvement in Sagittal Spinal Alignment}

SVA improvement was significantly greater in patients with preoperative SVA $\geq 40 \mathrm{~mm}(20.4 \pm 44.7 \mathrm{~mm})$ than in patients with preoperative SVA $<40 \mathrm{~mm}(-2.4 \pm$ $28.9 \mathrm{~mm})$. SVA improvement in patients with preoperative SVA $\geq 40 \mathrm{~mm}$ correlated with preoperative LL ( $\mathrm{r}=$ $-0.39 ; \mathrm{p}<0.03)$ and PI - LL $(\mathrm{r}=0.54 ; \mathrm{p}<0.01)$ (Table 4). Multiple regression analysis showed that preoperative PI LL $($ beta $=0.62 ; \mathrm{p}<0.01)$ and symptom duration (beta $=$

TABLE 3. Radiographic improvement and CSA and \%FI of PVM according to preoperative SVA

\begin{tabular}{|c|c|c|c|}
\hline \multirow[b]{2}{*}{ Variable } & \multicolumn{2}{|c|}{ Preop SVA* } & \multirow[b]{2}{*}{$p$ Value } \\
\hline & $\begin{array}{l}\geq 40 \mathrm{~mm} \\
(\mathrm{n}=30)\end{array}$ & $\begin{array}{l}<40 \mathrm{~mm} \\
(\mathrm{n}=31)\end{array}$ & \\
\hline Age (yrs) & $71.9 \pm 9.3$ & $66.9 \pm 9.2$ & 0.04 \\
\hline Male/female (no.) & $13 / 17$ & $17 / 14$ & 0.45 \\
\hline SVA improvement $(\mathrm{mm}) \dagger$ & $20.4 \pm 44.7 \S$ & $-2.4 \pm 28.9$ & 0.02 \\
\hline LL improvement $\left({ }^{\circ}\right) \ddagger$ & $4.6 \pm 7.8 \S$ & $0.3 \pm 9.6$ & 0.06 \\
\hline PT improvement $\left({ }^{\circ}\right) \dagger$ & $0.3 \pm 4.5$ & $-0.4 \pm 5.0$ & 0.60 \\
\hline \multicolumn{4}{|l|}{ CSA of PVM $\left(\mathrm{cm}^{2}\right)$} \\
\hline L2-3 & $42.9 \pm 9.5$ & $44.9 \pm 11.6$ & 0.46 \\
\hline L3-4 & $43.6 \pm 11.1$ & $45.9 \pm 10.8$ & 0.43 \\
\hline L4-5 & $40.7 \pm 9.8$ & $45.3 \pm 10.4$ & 0.08 \\
\hline L2-5 & $42.4 \pm 8.6$ & $45.2 \pm 9.9$ & 0.25 \\
\hline \multicolumn{4}{|l|}{$\% \mathrm{FI}$ of PVM (\%) } \\
\hline L2-3 & $17.4 \pm 7.3$ & $15.2 \pm 9.4$ & 0.32 \\
\hline L3-4 & $21.8 \pm 7.7$ & $20.6 \pm 11.7$ & 0.66 \\
\hline L4-5 & $33.0 \pm 11.1$ & $26.0 \pm 12.3$ & 0.03 \\
\hline L2-5 & $20.8 \pm 10.2$ & $24.0 \pm 7.5$ & 0.17 \\
\hline $\begin{array}{l}\text { Values are shown as mear } \\
\text { (Value before surgery) - } \\
\text { (Value at final follow-up) - } \\
\text { Significantly different befo }\end{array}$ & $\begin{array}{l}\text { at final follow- } \\
\text { e before surge } \\
\text { sus after surg }\end{array}$ & $<0.01)$. & \\
\hline
\end{tabular}

TABLE 4. Variables correlating with SVA improvement in patients with preoperative SVA $\geq 40 \mathrm{~mm}$

\begin{tabular}{lcc}
\hline Preop Variable & $r$ & $p$ Value \\
\hline Age & 0.07 & 0.73 \\
\hline Symptom duration & -0.29 & 0.12 \\
\hline $\mathrm{LL}\left({ }^{\circ}\right)$ & -0.39 & 0.03 \\
\hline $\mathrm{SS}\left(^{\circ}\right)$ & 0.04 & 0.82 \\
\hline $\mathrm{PT}\left(^{\circ}\right)$ & 0.16 & 0.40 \\
\hline $\mathrm{PI}\left(^{\circ}\right)$ & 0.16 & 0.40 \\
\hline $\mathrm{PI}-\mathrm{LL}\left({ }^{\circ}\right)$ & 0.54 & $<0.01$ \\
\hline JOA score (points) & 0.04 & 0.83 \\
\hline VAS score & & \\
\hline LBP & 0.13 & 0.50 \\
\hline Leg pain & -0.03 & 0.86 \\
\hline Leg numbness & -0.34 & 0.07 \\
\hline CSA of PVM (L4-5) & -0.21 & 0.28 \\
\hline$\% F I$ of PVM (L4-5) & 0.10 & 0.60 \\
\hline
\end{tabular}

$-0.40 ; \mathrm{p}<0.05)$ were independently associated with SVA improvement in patients with preoperative SVA $\geq 40 \mathrm{~mm}$ (Table 5).

\section{Deformity Subgroup Analyses}

The preoperative clinical characteristics of Groups D and $\mathrm{N}$ are summarized in Table 6 . The preoperative JOA score and VAS score for LBP, leg pain, and leg numbness were not significantly different between the groups. At the final follow-up evaluation, the mean JOA score was $24.8 \pm 3.5$ points in Group D and $22.9 \pm 4.1$ points in Group N; the mean VAS score for LBP was $21.2 \pm$ $28.5 \mathrm{~mm}$ in Group D and $25.1 \pm 27.7 \mathrm{~mm}$ in Group N ; the mean VAS score for leg pain was $20.2 \pm 30.2 \mathrm{~mm}$ in Group D and $26.4 \pm 37.3 \mathrm{~mm}$ in Group N; and the mean VAS score for leg numbness was $22.3 \pm 33.2 \mathrm{~mm}$ in Group D and $22.1 \pm 26.2 \mathrm{~mm}$ in Group N (Figs. 3 and 4). These values were not significantly different between groups.

\section{Clinical Outcomes According to the Change in SVA}

Table 7 shows the clinical results for the SVA-improved and SVA-increased groups. There were no statistically significant differences in the JOA score improvement ratio or the improvements in the VAS scores for LBP, leg pain, and leg numbness between the 2 groups.

TABLE 5. Multiple regression analysis of SVA improvement in patients with preoperative SVA $\geq 40 \mathrm{~mm}^{*}$

\begin{tabular}{lcccc}
\hline \multicolumn{1}{c}{ Variable } & B & SE B & Beta & $p$ Value \\
\hline PI - LL & 1.78 & 0.42 & 0.62 & $<0.001$ \\
\hline Symptom duration & -0.48 & 0.17 & -0.4 & 0.011 \\
\hline
\end{tabular}

$B=$ partial regression coefficient Beta $=$ standardized partial regression coef ficient; $\mathrm{SE}=$ standard error of estimate.

${ }^{*} \mathrm{R}=0.67 ; r^{2}=0.45 ;$ adjusted $r^{2}=0.41$. 
TABLE 6. Preoperative clinical characteristics in patients with a preoperative SVA $\geq 40 \mathrm{~mm}$

\begin{tabular}{lccc}
\hline \multicolumn{1}{c}{ Variable } & Group D $(n=16)^{*}$ & Group N $(n=14)^{*}$ & $p$ Value \\
\hline SVA $(\mathrm{mm})$ & $79.3 \pm 30.5$ & $68.3 \pm 32.7$ & 0.35 \\
\hline Age $(\mathrm{yrs})$ & $74.5 \pm 9.5$ & $68.9 \pm 8.3$ & 0.10 \\
\hline JOA score (points) & $15.4 \pm 5.3$ & $12.4 \pm 4.8$ & 0.12 \\
\hline VAS & & & \\
\hline LBP & $43.6 \pm 30.8$ & $48.7 \pm 32.7$ & 0.66 \\
\hline Leg pain & $65.5 \pm 31.7$ & $58.9 \pm 27.5$ & 0.55 \\
\hline Leg numbness & $44.6 \pm 29.1$ & $41.4 \pm 26.6$ & 0.76 \\
\hline
\end{tabular}

* Values are shown as mean $\pm S D$.

\section{Discussion}

MEL has several advantages over other microsurgical procedures for posterior soft tissues. It is minimally invasive to the paraspinal muscles because the tubular retractor enables gentle tissue dissection and minimizes retraction of the paraspinal muscles. ${ }^{8,13,15}$ The radiographic changes that occur after this procedure are similar to those that occur naturally over time in LSS. ${ }^{22}$ Therefore, clinical outcomes after this procedure can provide useful information about the pathology of LSS.

In the current study, we made 2 important clinical observations. First, preoperative PI - LL and symptom duration were independently associated with SVA improvement in LSS patients with preoperative SVA $\geq 40 \mathrm{~mm}$. Second, PVM degeneration at L4-5 was significantly greater in patients with preoperative SVA $\geq 40 \mathrm{~mm}$ than in patients with SVA $<40 \mathrm{~mm}$.

The finding that preoperative PI - LL was independently associated with SVA improvement in LSS patients with preoperative SVA $\geq 40 \mathrm{~mm}$ indicates that SVA improvements after MEL tend to be better when preoperative PI - LL is large. According to the Scoliosis Research Society-Schwab classification, a large PI - LL value in patients with adult spinal deformity indicates sagittal imbalance. ${ }^{17}$ However, in patients with degenerative lumbar

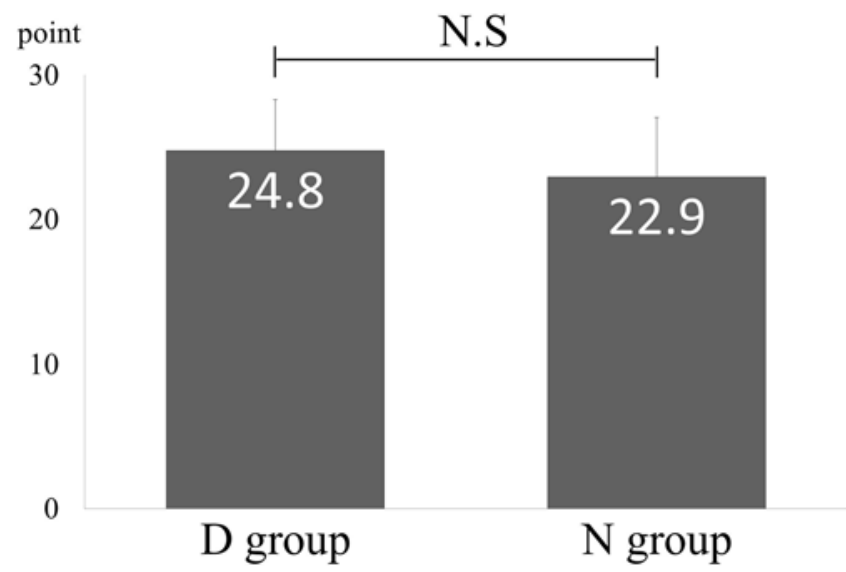

FIG. 3. JOA scores for patients in Groups $D$ and $N$ at the final follow-up evaluation $(p=0.21)$. N.S = not significant.

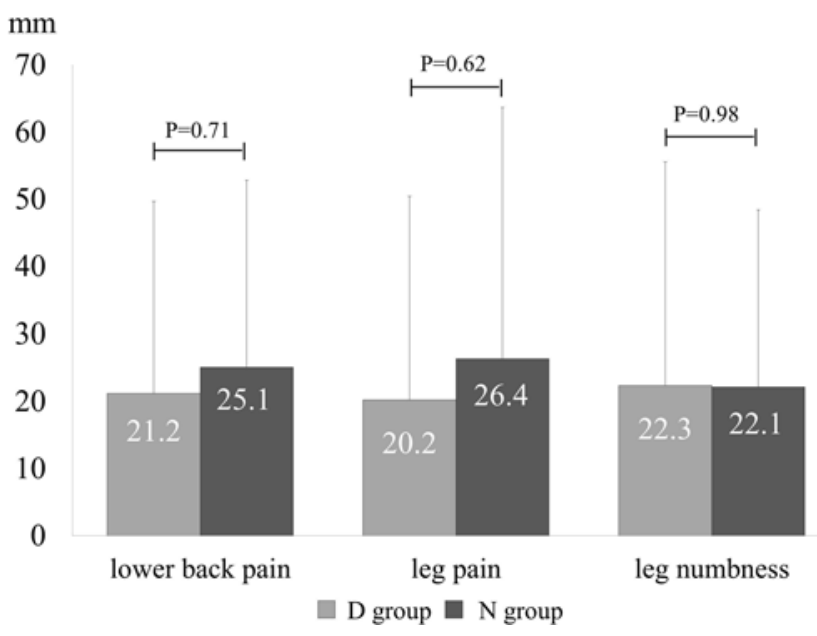

FIG. 4. Bar graphs showing the VAS scores for LBP, leg pain, and leg numbness in the patients in Groups $D$ and $\mathrm{N}$ at the final follow-up evaluation. Error bars indicate the standard deviation.

disease such as LSS, anterior displacement of the C-7 plumb line and the loss of lordosis occur as a protective mechanism to avoid neurological symptoms. ${ }^{1}$ In patients with LSS in the present study, the anterior shift of the C-7 plumb line did not likely result from severe structural deformity. Thus, the high PI - LL value in LSS patients likely resulted from an abnormal posture used to avoid neurological symptoms. Decompression surgery without corrective fusion surgery can improve sagittal spinal alignment in patients with LSS. ${ }^{6}$

We also found that SVA improvement after MEL in patients with preoperative SVA $\geq 40 \mathrm{~mm}$ tended to be worse in patients who had symptoms for a long duration. Abnormal spinal alignment in the sagittal plane while standing is influenced by decreased paraspinal muscle strength, lumbar lordosis, and spinal mobility. ${ }^{21}$ Continuous extension of the paraspinal muscles caused by long-term forward-bending posture increases pressure on those muscles and promotes local ischemia. ${ }^{21}$ Thus, we speculate that long periods of positioning in a forward-bending posture

TABLE 7. Clinical outcomes grouped according to change in SVA

\begin{tabular}{|c|c|c|c|}
\hline Variable & $\begin{array}{l}\text { SVA-Improved } \\
\text { Group }(n=39)^{*}\end{array}$ & $\begin{array}{l}\text { SVA-Increased } \\
\text { Group }(n=22)^{*}\end{array}$ & $\begin{array}{c}\mathrm{p} \\
\text { Value }\end{array}$ \\
\hline Age (yrs) & $69.0 \pm 10.7$ & $70.1 \pm 8.2$ & 0.71 \\
\hline $\begin{array}{l}\text { Improvement ratio of JOA } \\
\text { score }(\%) \dagger\end{array}$ & $76.2 \pm 19.1$ & $70.2 \pm 29.1$ & 0.38 \\
\hline \multicolumn{4}{|l|}{$\begin{array}{l}\text { Improvement of VAS } \\
\text { score }(\mathrm{mm}) \ddagger\end{array}$} \\
\hline LBP & $31.7 \pm 35.5$ & $27.7 \pm 26.2$ & 0.68 \\
\hline Leg pain & $44.1 \pm 43.2$ & $45.4 \pm 38.5$ & 0.91 \\
\hline Leg numbness & $18.5 \pm 37.2$ & $32.3 \pm 37.7$ & 0.21 \\
\hline
\end{tabular}

J Neurosurg Spine Volume 25 • July 2016 
to avoid neurological symptoms can make SVA improvement after decompression surgery less likely.

PVM degeneration at L4-5 was significantly greater in patients with preoperative SVA $\geq 40 \mathrm{~mm}$ than in patients with SVA $<40 \mathrm{~mm}$. According to the Scoliosis Research Society-Schwab classification, $40 \mathrm{~mm}$ is a cutoff SVA value for modifier grades, indicating outcome scores that have been demonstrated to have a strong clinical impact. ${ }^{17}$ Lee et al. reported that fat infiltration into the PVM was higher in patients with a degenerative flat back than in normal controls, and this change was more significant in the lower lumbar back. ${ }^{12}$ In contrast, PVM degeneration was most prominent at the level of the affected nerve root and 1 level below in patients with neurological symptoms. ${ }^{18} \mathrm{In}$ this study, all but 1 patient underwent surgery at L3 -4 and/ or L4-5. For these structural and neurological reasons, PVM degeneration at L4-5 was more marked in patients with forward-bending posture than in patients without forward-bending posture.

In patients with adult spinal deformity, progressive positive sagittal spinal alignment resulted in increasing PT, or pelvic retroversion, to compensate for the anterior translation of the spine. ${ }^{16}$ In this study, PT did not significantly decrease after surgery, despite SVA improvement. This finding indicates that compensation by pelvic retroversion did not occur in LSS patients before surgery. It is possible that the mechanism and pathology of forward-bending posture in LSS patients is different from that in adult spinal deformity patients. Similarly, it appears that the significance of PI - LL is different in patients with LSS versus those with adult spinal deformity.

The current study yielded important findings. Our study revealed that improvement in forward-bending posture, which is associated with health-related QOL and LBP, can be predicted from PI - LL and symptom duration. This information can help clinicians predict SVA improvement after decompression surgery in LSS patients based on a few preoperative radiological and clinical factors.

This study has 3 limitations. First, this was a retrospective study, and the indications for this surgical procedure were limited in patients with degenerative spondylolisthesis or degenerative lumbar scoliosis. Second, the sample size in each group was not sufficient to yield substantial effects. Further studies based on a larger sample size should be performed to confirm the present results. Third, the timing of the lateral standing radiographs after surgery was relatively late. In this study, the mean timing of lateral standing films at the final follow-up was approximately 30 months after surgery. Various factors are affected by the passage of time. Earlier timing of radiographs would make it possible to more directly evaluate the effect of decompression surgery on spinopelvic parameters.

\section{Conclusions}

This study showed that preoperative PI - LL and symptom duration were independently associated with SVA improvement in LSS patients with forward-bending posture, and PVM degeneration at the lower lumbar level was significantly greater in patients with preoperative SVA $\geq 40$ $\mathrm{mm}$ than in patients with SVA $<40 \mathrm{~mm}$.

\section{References}

1. Barrey C, Jund J, Noseda O, Roussouly P: Sagittal balance of the pelvis-spine complex and lumbar degenerative diseases. A comparative study about 85 cases. Eur Spine J 16:14591467, 2007

2. Chen YY, Pao JL, Liaw CK, Hsu WL, Yang RS: Image changes of paraspinal muscles and clinical correlations in patients with unilateral lumbar spinal stenosis. Eur Spine J 23:999-1006, 2014

3. D'hooge R, Cagnie B, Crombez G, Vanderstraeten G, Dolphens M, Danneels L: Increased intramuscular fatty infiltration without differences in lumbar muscle cross-sectional area during remission of unilateral recurrent low back pain. Man Ther 17:584-588, 2012

4. Dohzono S, Toyoda H, Matsumoto T, Suzuki A, Terai H, Nakamura H: The influence of preoperative spinal sagittal balance on clinical outcomes after microendoscopic laminotomy in patients with lumbar spinal canal stenosis. J Neurosurg Spine 23:49-54, 2015

5. Endo K, Suzuki H, Tanaka H, Kang Y, Yamamoto K: Sagittal spinal alignment in patients with lumbar disc herniation. Eur Spine J 19:435-438, 2010

6. Fujii K, Kawamura N, Ikegami M, Niitsuma G, Kunogi J: Radiological improvements in global sagittal alignment after lumbar decompression without fusion. Spine (Phila Pa 1976) 40:703-709, 2015

7. Glassman SD, Bridwell K, Dimar JR, Horton W, Berven S, Schwab F: The impact of positive sagittal balance in adult spinal deformity. Spine (Phila Pa 1976) 30:2024-2029, 2005

8. Ikuta K, Arima J, Tanaka T, Oga M, Nakano S, Sasaki K, et al: Short-term results of microendoscopic posterior decompression for lumbar spinal stenosis. Technical note. J Neurosurg Spine 2:624-633, 2005

9. Jackson RP, McManus AC: Radiographic analysis of sagittal plane alignment and balance in standing volunteers and patients with low back pain matched for age, sex, and size. A prospective controlled clinical study. Spine (Phila Pa 1976) 19:1611-1618, 1994

10. Jang JS, Lee SH, Kim JM, Min JH, Han KM, Maeng DH: Can patients with sagittally well-compensated lumbar degenerative kyphosis benefit from surgical treatment for intractable back pain? Neurosurgery 64:115-121, 2009

11. Landis JR, Koch GG: The measurement of observer agreement for categorical data. Biometrics 33:159-174, 1977

12. Lee JC, Cha JG, Kim Y, Kim YI, Shin BJ: Quantitative analysis of back muscle degeneration in the patients with the degenerative lumbar flat back using a digital image analysis: comparison with the normal controls. Spine (Phila Pa 1976) 33:318-325, 2008

13. Mayer TG, Vanharanta H, Gatchel RJ, Mooney V, Barnes D, Judge L, et al: Comparison of CT scan muscle measurements and isokinetic trunk strength in postoperative patients. Spine (Phila Pa 1976) 14:33-36, 1989

14. Mengiardi B, Schmid MR, Boos N, Pfirrmann CW, Brunner F, Elfering A, et al: Fat content of lumbar paraspinal muscles in patients with chronic low back pain and in asymptomatic volunteers: quantification with MR spectroscopy. Radiology 240:786-792, 2006

15. Pao JL, Chen WC, Chen PQ: Clinical outcomes of microendoscopic decompressive laminotomy for degenerative lumbar spinal stenosis. Eur Spine J 18:672-678, 2009

16. Schwab F, Patel A, Ungar B, Farcy JP, Lafage V: Adult spinal deformity-postoperative standing imbalance: how much can you tolerate? An overview of key parameters in assessing alignment and planning corrective surgery. Spine (Phila Pa 1976) 35:2224-2231, 2010

17. Schwab F, Ungar B, Blondel B, Buchowski J, Coe J, Deinlein D, et al: Scoliosis Research Society-Schwab adult spinal 
deformity classification: a validation study. Spine (Phila Pa 1976) 37:1077-1082, 2012

18. Shafaq N, Suzuki A, Matsumura A, Terai H, Toyoda H, Yasuda H, et al: Asymmetric degeneration of paravertebral muscles in patients with degenerative lumbar scoliosis. Spine (Phila Pa 1976) 37:1398-1406, 2012

19. Suzuki H, Endo K, Kobayashi H, Tanaka H, Yamamoto K: Total sagittal spinal alignment in patients with lumbar canal stenosis accompanied by intermittent claudication. Spine (Phila Pa 1976) 35:E344-E346, 2010

20. Takahashi K, Miyazaki T, Takino T, Matsui T, Tomita K: Epidural pressure measurements. Relationship between epidural pressure and posture in patients with lumbar spinal stenosis. Spine (Phila Pa 1976) 20:650-653, 1995

21. Takemitsu Y, Harada Y, Iwahara T, Miyamoto M, Miyatake Y: Lumbar degenerative kyphosis. Clinical, radiological and epidemiological studies. Spine (Phila Pa 1976) 13:13171326,1988

22. Toyoda H, Nakamura H, Konishi S, Dohzono S, Kato M, Matsuda H: Clinical outcome of microsurgical bilateral decompression via unilateral approach for lumbar canal stenosis: minimum five-year follow-up. Spine (Phila Pa 1976) 36:410-415, 2011

\section{Disclosures}

The authors report no conflict of interest concerning the materi- als or methods used in this study or the findings specified in this paper.

\section{Author Contributions}

Conception and design: Dohzono. Acquisition of data: Toyoda, Dohzono, Matsumoto. Analysis and interpretation of data: Dohzono. Drafting the article: Dohzono. Critically revising the article: Toyoda. Reviewed submitted version of manuscript: Toyoda. Approved the final version of the manuscript on behalf of all authors: Toyoda. Statistical analysis: Dohzono, Takahashi. Administrative/technical/material support: Takahashi, Suzuki, Terai. Study supervision: Nakamura.

\section{Supplemental Information \\ Previous Presentations}

Portions of this work were presented in special poster form on June 10, 2015, at the 42nd Annual Meeting of the International Society for the Study of the Lumbar Spine, San Francisco, California.

\section{Correspondence}

Hiromitsu Toyoda, Department of Orthopaedic Surgery, Osaka City University Graduate School of Medicine, 1-4-3 Asahimachi, Abeno-ku, Osaka 545-8585, Japan. email: h-toyoda@msic.med. osaka-cu.ac.jp. 